\title{
REVIEWS AND ANNOUNCEMENT
}

Einheimische Nutzhölzer und ihre Bestimmung nach makroskopischen Merkmalen. H. Sachsse, 160 pp., many half-tone plates, 1984. Pareys Studientexte 44, Paul Parey, Hamburg, Berlin. Price: DM 36 (paper).

This book provides anatomical, technological and general information on 29 common timber species from West Germany as well as a macroscopic (lens) key to the identification of their wood. The author does not pretend to give thorough background information on wood structure, but certainly succeeds in explaining basic facts and the possibilities and limitations of macroscopic wood identification in the introductory chapters. Ample and very apt illustrations will contribute much to the success any user of the keys will have in identifying softwoods and ring- or diffuse-porous hardwoods.

For each species the text recapitulates the diagnostic macroscopic features used in the identification process and summarises other important wood structural features. Furthermore there are useful data on durability, wood protection, properties such as density, shrinkage, modulus of elasticity, strength parameters, drying, and on uses and miscellaneous other characteristics. The illustrations are of a high quality and include $\times 10$ surface views of the three planes, a $\times 90$ SEM photograph showing threedimensional microstructure, and a full plate with 4 light micrographs for each species.

A few minor shortcomings could perhaps be remedied in a revised edition. On p. 15 Poplar and Beech are apparently mixed up in the labelling of the major fibre types. Nowhere in the text is the reader allerted for the intermediate category of semi-ring-porous hardwoods. The latter are classified as diffuse-porous, and the author even puts Walnut on record to have earlywood and latewood pores of almost the same diameter, whilst the illustrations clearly show marked differences. One also wonders about the sample size on which the key is based, when one notices that Sorbus aucuparia is the only species credited with conspicuously concentric annual rings. This is obviously true for all species, especially if only slender stems or branches are considered. A comparison of the softwood key with illustrations in Schweingruber's Microscopic Wood Anatomy Atlas (1978) also raises doubts on the diagnostic value of some of the characters used. For instance Abies alba, which is credited with a high proportion of latewood, is illustrated by Schwein- gruber by 3 samples with a very low latewood percentage.

In other respects, however, the general quality of text and illustrations can only inspire praise.

Pieter Baas

(Multilingual Glossary of Terms used in Wood Anatomy), Persian version. Parviz Niloufari, 60 pp. text +33 pages of plates and line-drawings, 1984. Donya Publications, Tehran, Iran. Price unknown (paper).

This publication provides a Persian version of the 1964 IAWA Multilingual Glossary of Terms used in Wood Anatomy. As such it will certainly be a helpful tool in the training of wood anatomists in Iran, to be welcomed as much as earlier versions of the glossary in Dutch, Chinese and Icelandic. For teaching purposes the illustrations at the end of the book will also be most useful. One must, however, sound a critical note about the haphazard way in which these have been assembled from well-known textbooks without even adjusting the labelling or in most cases without citing the source. Students of wood anatomy in Iran may also become confused by the multilingual nature of the labelling: English, French, Italian or German, depending on the source from which the illustrations were taken. Sometimes even complete pages with incomplete legends have been copied so that, for instance, one page with a composite plate from Grosser's 'Die Hölzer Mitteleuropas' (1977) containing twelve illustrations has a legend starting with '... brechungen' of fig. 7 and leaves the previous 6 figures unexplained. As long as the purpose of disseminating wood anatomical knowledge in Iran is served with this publication, we should not be too hard on the author for these shortcomings. On the other hand the lack of source citation comes somewhat unexpectedly from Prof. Niloufari, who is well-known throughout the IAWA for his courteous New Year's greetings sent to most members every year.

Pieter Baas

Tropical timbers of the world. Martin Chudnoff, v +464 pp., illus., 1984. United States Department of Agriculture, Forest Service, Agriculture Handbook Number 607. Available from the Superintendent of Documents, U.S. Government Printing Office, 710 N. Capitol Street, Washington, D.C. 20402, U.S.A. Price: US\$ 16.00 (paper). 